\title{
Oprocesso do cuidar/cuidado nas representações sociais de cuidadores de pacientes sequelados por acidente vascular cerebral
}

\author{
Jeferson Santos Araujo \\ Silvio Eder Dias da Silva² \\ Mary Elizabeth de Santana ${ }^{3}$ \\ Vander Monteiro da Conceição ${ }^{4}$ \\ Esleane Vilela Vasconcelos ${ }^{5}$
}

Recebido em: 13/06/2011

Aceito em: 23/11/2011

O estudo objetiva identificar e analisar as representações sociais dos cuidadores de pacientes sequelados após Acidente Vascular Cerebral acerca do cuidado prestado. Trata-se de uma pesquisa do tipo exploratório-descritiva, com uma abordagem qualitativa. Empregou-se o método preceitos da Teoria das Representações Sociais de Moscovici. Após a leitura flutuante dos textos produzidos, as unidades de análise emergidas foram agrupadas e denominadas de: O cuidado ao indivíduo com AVC; as sequelas, a atenção e o cuidado, e o cuidador e o cuidar. O estudo contribuiu para a caracterização do cuidado ao indivíduo sequelado.

Descritores: Cuidadores, Cuidados de Enfermagem, Psicologia Social.

\section{The process of care/caring in the social representations of caregivers of patients with sequelae of stroke}

The study aims to identify and analyze the social representations of caregivers of stroke sequelae after the care provided. It is a research-type exploratory-descriptive, with a qualitative approach. The method precepts of Social Representation Theory of Moscovici was employed. After floating reading of the texts produced, the units of analysis emerged were grouped and named:The care of individuals presenting stroke, sequelae, the attention and the care and the caregiver and to care. The study contributed to the characterization of the care to squealed individual.

Descriptors: Caregivers, Nursing Care, Social Psychology.

El proceso de atención/atención en las representaciones sociales de los cuidadores de pacientes con secuelas de accidente cerebrovascular El estudio tiene como objetivo identificar y analizar las representaciones sociales de los cuidadores de las secuelas de accidente cerebrovascular después de la atención recibida. Se trata de una investigación exploratorio-descriptivo, con un enfoque cualitativo para el método que se utilizó preceptos de la Teoría de las Representaciones Sociales de Moscovici. Después de leer los textos producidos flotantes, las unidades de análisis se agruparon y surgió el nombre: El cuidado de las personas con accidente cerebrovascular, las secuelas, el cuidador y el cuidado y atención y cuidado. El estudio contribuyó a la caracterización de la atención para el sujeto con secuela.

Descriptores: Cuidadores, Cuidados de Enfermería, Psicología Social.

\section{INTRODUÇÃO}

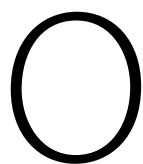

Acidente Vascular Cerebral (AVC) é uma doença incapacitante e fatal. A maioria dos pacientes acometidos morrem nos primeiros anos após o acidente, e os que sobrevivem costumam apresentar perda na capacidade de deambular, falar, de desenvolver suas atividades diárias e de cuidar de si, dependendo desta maneira de cuidados constantes de terceiros, neste caso, um cuidador ${ }^{(1)}$.

A ocupação de cuidador integra a Classificação Brasileira de Ocupações - CBO - sob o código 5162, que define o cuidador como alguém que cuida a partir dos objetivos estabelecidos por instituições especializadas ou responsáveis diretos, zelando pelo bem-estar do ser. É a pessoa que presta cuidados a quem esteja necessitando, por estar acamado, com limitações físicas ou mentais, com ou sem remuneração. O cuidador é de fundamental importância para a reabilitação e para o atendimento às necessidades físicas cotidianas do portador de AVC no seguimento das orientações para a saúde, bem-estar, segurança e conforto, e ainda no respeito e incentivo ao estímulo, à autonomia e independência.

Ao prestar cuidados, o cuidador passa a dispor de menos tempo para cuidar de si, passa a descansar menos e trabalhar

1 Enfermeiro. Especialista em Enfermagem do Trabalho. Vinculado ao Núcleo de Pesquisa EPOTENA. E-mail: jeferson-ma@ig.com.br.

2 Enfermeiro. Doutor em Enfermagem pelo DINTER UFPA/UFSC. Vinculado ao Núcleo de Pesquisa GEHCES - Grupo de Estudo de História do Conhecimento da Enfermagem e Saúde/UFSC. Professor Adjunto da Faculdade de Enfermagem da UFPA.

3 Enfermeira. Doutora em Enfermagem pela Escola de Enfermagem de Ribeirão Preto da USP. Vinculada ao Núcleo de Pesquisa EPOTENA. Professora Adjunto da Faculdade de Enfermagem da UFPA.

4 Enfermeiro. Especialista em Integralidade da Atenção Oncológica. Vinculado ao Núcleo de Pesquisa EPOTENA.

5 Enfermeira. Especialista em Enfermagem Cirúrgica e Terapia Intensiva. Atua no Hospital Ophir Loyola e no SESPA. 
mais, muitas vezes privando-se do convívio social, visto que o doente portador de AVC se torna o centro das atenções. Isso leva o cuidador a reacomodar suas práticas diárias às atividades exigidas pela evolução da doença, submetendo-se assim, na maioria dos casos, a uma sobrecarga física e emocional relacionada à intensidade dos cuidados $\operatorname{prestados}^{(2)}$.

\section{OBJETIVO}

Neste contexto, o presente estudo objetiva identificar e analisar as representações sociais dos cuidadores de pacientes sequelados após AVC, acerca do cuidado prestado.

\section{MATERIAL E MÉTODOS}

Trata-se de estudo exploratório com abordagem qualitativa do tipo estudo de caso, que utiliza como preceitos as vertentes da pesquisa social das representações sociais. Tais representações buscam a utilização de uma abordagem que observa como relevante o sujeito e sua relação com o ambiente no qual está inserido, tentando assim uma compreensão das estruturas simbólicas dos cuidadores de pacientes vítimas de AVC e suas representações frente às sociedades da qual fazem parte ${ }^{(3)}$.

A representação social é uma forma de saber do senso comum, criada no psicossocial de cada ser, que enriquece os saberes e práticas dos grupos que o dividem através da comunicação, dos símbolos, das linguagens e dos gestos, dos seus conhecimentos e suas características em comum, de forma a consolidar as relações do processo ensino/aprendizagem que favoreçam a criação de um novo saber que os guiem no seu dia a dia com o cuidado(4).

A amostra foi composta por 20 cuidadores informais que acompanhavam seus familiares em consultas ambulatoriais no Hospital Ophir Loyola e na clínica neurológica UNINEURO, ambos referência no atendimento neurológico em Belém do Pará, e que manifestaram disponibilidade e interesse em participar do estudo, após o conhecimento dos objetivos e da assinatura do termo de consentimento.

A escolha dos cuidadores ocorreu através de amostragem por conveniência e o número de cuidadores foi determinado através do princípio da pesquisa qualitativa em que determina o fim da pesquisa decorrente do momento que ocorre a saturação dos dados. Foram excluídos os cuidadores que apresentavam vínculo com o cuidar ao paciente há menos de um ano, pelo fato de estarem há pouco tempo no desenvolvimento de cuidados diretos.

Os dados foram obtidos por meio de um questionário com perguntas semiestruturadas e semidirigidas destinadas aos cuidadores, com o objetivo de obter por meio de suas produções textuais, as representações sociais sobre a patologia.

Para proceder à análise do material coletado, empregamos a técnica de análise de conteúdo (análise temática), que pode ser compreendida como a expressão mais comumente utilizada para representar o tratamento dos dados de uma pesquisa qualitativa, ressalvando-se que o termo significa mais do que um procedimento técnico. Faz parte de uma histórica busca teórica e prática no campo das investigações sociais ${ }^{(5)}$.

Procedeu-se ao levantamento de temas significativos a partir das histórias contadas pelos cuidadores correspondentes aos textos produzidos. Em seguida passou-se a traduzir cada história em um discurso elaborado que, em suma, acredita-se expressarem as representações sociais com o processo cuidar/cuidado dos cuidadores ${ }^{(6)}$.

Após a leitura flutuante dos textos produzidos, as unidades de análise emergidas foram agrupadas e, a seguir, submetidas a uma exploração para melhor compreensão do objeto da pesquisa, mediante conteúdos considerados mais significativos em cada texto, de forma a se consolidarem em três unidades temáticas assim denominadas: $\mathrm{O}$ cuidado ao indivíduo com AVC; As sequelas, a atenção e cuidado; e, O cuidador e o cuidar.

Ressalta-se que essa pesquisa passou pelo comitê de ética em pesquisa do Instituto de Ciências da Saúde da Universidade Federal do Pará sobre o no de parecer 086/10, e respeita todas as diretrizes e normas do Conselho Nacional de Saúde, Resolução nº. 196.

\section{RESULTADOS E DISCUSSÕES O cuidado ao indivíduo com AVC} As ideias agrupadas nos textos produzidos por (55\%) dos depoentes estão relacionadas ao sentimento de sofrimento, onde o cuidador se envolve com o processo de cuidar como se tais problemas cognitivos gerados pelo AVC também fossem seus. Isso acaba por levá-los ao sofrimento, não na mesma intensidade da dor do ser cuidado, mas na intensidade da dor semelhante à do outro. Tais características podem ser observadas nas falas exemplificadas abaixo:

"A pessoa tem que ter paciência, devido ao estresse e tem que ter a aceitação do doente. Sofro com ele, mas tenho que ser forte [...." (A1)

"A vida da pessoa muda totalmente. O papai ficou todo mudado, só que a mudança dele foi para pior. Isso me deixa muito triste." (A11)

"[...] depois que meu pai teve derrame, presenciei a cada dia sua vida acabando e a minha também. Não aguento ver ele assim." (A19)

O antropofagismo sentimental expresso nas representações dos cuidadores procede devido à sensibilidade e à identificação com o cuidado, uma vez que o cuidar, para ser um processo de solicitude, exige a identidade com o ato, de forma a superar as dificuldade e as limitações. Assim sendo, para serem fidedignos ao cuidado, os cuidadores devem envolver-se com que fazem ${ }^{(7)}$. 
Cuidar de pessoas vítimas de AVC mobiliza muitos sentimentos antagônicos: amor e raiva, paciência e intolerância, carinho, tristeza, irritação, desânimo, pena, revolta, insegurança, negativismo e solidão. Todos esses sentimentos colocam muitas dúvidas quanto aos cuidados, sobretudo os sentimentos negativos, que podem causar sofrimento e dor ${ }^{(8)}$.

O cuidador é exposto a diversos eventos causadores de sofrimento. Ele sofre por não saber do futuro do ser cuidado, pelas incertezas quanto à doença e o tratamento do AVC, e por temer a possibilidade do incapacitado. $O$ cuidador sofre assumindo o sofrimento junto com o acometido de AVC, pelo fato de vê-lo sofrendo e, também, por sentir-se impotente, por saber-se incapaz de livrar o outro do sofrimento.

O sofrimento apresentado com o surgimento do fenômeno social dos cuidadores desencadeou um processo de elaboração nos planos individuais e coletivos de teorias que combinam valores, crenças, atitudes e informações, que permitiram que esses seres sociais guiassem seu saber frente ao envolvimento com o ser cuidado.

Para as representações sociais, é pelo estudo e divulgação de tais saberes e teorias que o indivíduo organiza uma visão coerente do objeto de cuidado e do ser humano, ao mesmo tempo em que procura negociar um espaço de aceitação e inclusão nos grupos com os quais interagem ${ }^{(6)}$. Nesse contexto, observa-se que os aspectos afetivos das representações sociais estiveram intimamente introjetados nos depoimentos do grupo pesquisado, sendo estas primordiais para o reconhecimento de uma realidade repleta de sofrimento ${ }^{(9)}$.

\section{As sequelas, a atenção e o cuidado}

A quantidade de sequelas mencionadas nos textos produzidos foi um fator relevante nas falas de $60 \%$ dos depoentes, uma vez que representam mais atenção requerida pelos cuidadores, sendo um agente implicante no processo de cuidado. Os textos em questão podem ser observados nos trechos abaixo:

"Depois do derrame, meu pai ficou assim, não anda mais e tudo depende da gente, é muito. Ele é um incômodo, pois deixo de fazer as coisas para fazer tudo que ele quer." (A9) "[...] antes ele fazia tudo, andava, resolvia os problemas dele, e agora ele mal consegue falar, até eu tenho que ajudar, essa sequela que eles falam que ele ficou, só prejudica as pessoas, tanto eu como ele." (A13)

"[...] Antes ele não era assim, ele fazia tudo, parece que quanto mais sequela ele tem pior fica para cuidar." (A20)

Para os cuidadores, quanto mais sequelas o receptor de cuidados apresentar, maior o tempo de atenção destinado a ele. A incapacidade gerada pelo AVC é relacionada à mudança, onde está incapaz e depende exclusivamente de outros e está mudado para pior, pois está ocasionando intrigas na vida do cuidador, em estado de deficiência total, sem autonomia de si.

As necessidades de cuidados às pessoas sequeladas por AVC são inúmeras. A começar pelo seu acentuado grau de comprometimento funcional para o provimento do autocuidado corporal, necessidades em graus variados da ajuda de outros para o desempenho das atividades da vida diária, sem as quais o bem-estar, a autoestima, a apresentação, convivência e inclusão social dessas pessoas seriam inviáveis ${ }^{(10)}$.

Quando os cuidadores percebem-se sobrecarregados, devido ao aumento da sua atenção para com o outro, tendem a sentir maiores níveis de cansaço e, consequentemente, a desempenharem suas funções além de suas capacidades, o que resulta numa situação de cuidado desequilibrada, normalmente acompanhada por resultados insatisfatórios, passando a sentir restrições também em relação à sua própria vida, ao cuidado de $\mathrm{si}^{(8)}$.

As representações sociais fazem com que o mundo seja o que pensamos que ele é ou deva ser, pois elementos novos são inseridos a todo instante em nosso pensamento, modificando sua estrutura a respeito dos objetos. Por isso, na representação dos cuidadores, o AVC gera grandes mudanças no paciente, à proporção que quanto mais sequelas apresentarem maiores serão as necessidades de cuidado e zelo ${ }^{(4)}$.

\section{O cuidador e o cuidar}

A atenção integral foi representada pelos cuidadores como restrita em alguns momentos. Os relatos ilustrados abaixo demonstram que, perante o AVC ou seus problemas associados, $30 \%$ dos cuidadores sentem-se inseguros e incapazes de realizar intervenções, sobretudo as emergenciais, pois acreditam que podem provocar falhas ao cuidar, levando o indivíduo a agravar mais o seu quadro de saúde.

"Agora eu fico sem saber o que fazer para ajudar, ela não fala quando tem dor, quando quer comer, ela fica sem ter as coisas, pois não sei o que ela quer." (A10)

"Eu não sei como lidar com ele, tenho medo de fazer alguma bobagem e acabar piorando a vida dele, o estado dele." (A5) "Não consigo entender o que eles falam e fica difícil ajudar. Eles consomem muito de mim e não sei mais o que fazer." (A11)

O sentimento de incapacidade permite ao cuidador se autoavaliar e, dessa forma, perceber se o cuidado prestado é satisfatório ou não. Logo podem surgir diversas atitudes diante dessas situações, onde alguns cuidadores procuraram melhor capacitação para o manejo desses doentes e outros apresentaram angústias e sentimentos negativos que podem vir a implicar na atenção em saúde dos indivíduos receptores do cuidado. 
No AVC, o indivíduo acometido apresenta perdas progressivas, e muitas vezes irreversíveis, assim como diversas mudanças, as quais acabam gerando situações inusitadas na convivência com os cuidadores. Esse fato pode levar ao aparecimento de insegurança e incapacidade de realizar intervenções geradas pelo excesso de cuidados prestados $^{(11)}$.

$O$ cuidador em diversos momentos é chamado a intervir em situações de risco de morte ao ser cuidado. A angústia e a insegurança, nessas circunstâncias, são extremas. Desde o doente, que sente a morte iminente, até todos os que se dedicam a ele e não querem perdê-lo. Nesse momento, o cuidador revela-se um ser sentimental e onipotente, dotado de medo e dúvidas que o prendem ao cuidado restrito ao ser dependente ${ }^{(12)}$.

Quanto à falta de segurança na realização dos cuidados emergenciais ao paciente, as noções conceituais das representações sociais auxiliam no entendimento de tal aspecto. Os cuidadores não incorporaram experiências prévias que os guiassem em sua dinâmica de cuidar cotidianamente, que enfatizassem um saber técnico que lhes gerasse confiança na execução de atividades cuidativas. Dessa forma, os cuidadores sentem-se inseguros em realizar dadas intervenções ${ }^{(4)}$.

\section{CONCLUSÃO}

As representações geradas pelo grupo estudado favoreceram a identificação e a análise das representações sociais acerca do cuidado prestado ao ser sequelado por AVC, sendo o cuidado entendido como uma tarefa árdua, visto que as representações atribuídas foram ancoradas à ideia de exaustão, permitindo afirmar que o cuidado era prestado em alguns momentos como obrigação, o que não representa então o real conceito de cuidado, que é atender às necessidades do outro com domínio e satisfação da assistência.

Entende-se que para prestar o cuidado é necessário, sobretudo preparo, tanto técnico quanto emocional. Dessa forma, os entrevistados demonstraram despreparo em sua assistência, uma vez que apresentaram o sentimento de angústia, que foi gerado em diversos momentos, seja no sofrer junto com o seu objeto de cuidado, ou na dependência que o outro tem para consigo, e na invalidez que o cuidador sente quando algo ultrapassa sua capacidade de assistir seu receptor de cuidados.

As representações sociais dos cuidadores auxiliam que o enfermeiro possa então elaborar ações que busquem a melhor adequação do prestador de cuidados em sua função, sobretudo estratégias de serviços em saúde para que junto à alta do paciente seja realizado o preparo desses cuidadores no ambiente familiar.

\section{Referências}

1. Makiyama TYM, Battisttella LR, Litvoc J, Martins LC. Estudo sobre a qualidade

de vida de pacientes hemiplégicos por acidente vascular cerebral e de seus

cuidadores. Acta Fisiatr. 2004;11(3):106-9.

2. Silva AL, Gonçalves LHT. Cuidado à pessoa idosa: estudos no contexto luso-

-brasileiro. Porto Alegre: Sulina; 2010.

3. Moscovici S. Representaçōes sociais: investigaçōes em psicologia social.

Petrópolis: Vozes; 2003.

4. Moscovici S. Representações sociais: investigações em psicologia social. $6^{\mathrm{a}}$ ed.

Rio de Janeiro: Vozes; 2009.

5. Bardin L. Análise de conteúdo. Lisboa: Ediçōes 70; 1977.

6. Jodelet D. Loucuras e representações sociais. Petrópolis: Vozes; 2005.

7. Boff L. Saber cuidar: ética do humano-compaixão pela terra. Petrópolis:
Vozes; 2008.

8. Karsch UMS, Leal MGS. Pesquisando cuidadores: visita a uma prática

metodológica. In: Karsch UMS, organizadora. Envelhecimento com dependência:

revelando cuidadores. São Paulo: Educ; 1998.

9. Jodelet D. As representaçōes sociais. Rio de Janeiro: EDUERJ; 2001.

10. Bocchi SCM. Vivenciando a sobrecarga ao vir-a-ser um cuidador familiar

de pessoa com acidente vascular cerebral (AVC): análise do conhecimento. Rev

Latinoam Enferm. 2004;12(1).

11. Mendonca FF, Garanhani ML, Martins VL. Cuidador familiar de sequelados de acidente vascular cerebral: significado e implicaçōes. Physis (Rio J.). 2008;18(1). 12. Campos EP. Quem cuida do cuidador: uma proposta para os profissionais de saúde. 3a ed. Rio de Janeiro: Vozes; 2007. 